08,09

\title{
Влияние примеси кислорода на эффективность образования комплексов с Н-связью и агрегацию центров окраски во фториде лития
}

\author{
(C) С.А. Небогин ${ }^{1}$, Л.И. Брюквина ${ }^{2,}$, Н.А. Иванов ${ }^{1}$, Д.С. Глазунов ${ }^{2}$ \\ ${ }^{1}$ Иркутский национальный исследовательский технический университет, \\ Иркутск, Россия \\ ${ }^{2}$ Институт лазерной фризики СО РАН (Иркутский филиал), \\ Иркутск, Россия \\ ฯ E-mail: Ibryukvina@mail.ru \\ (Поступила в Редакцию 29 июня 2016 г. \\ В окончательной редакции 20 сентября 2016 г.)
}

\begin{abstract}
Изучено влияние примесей на эффективность образования центров окраски и молекулярных комплексов с водородной связью под воздействием различных видов излучений в выращенных на воздухе кристаллах фторида лития. Представлены результаты экспериментов по измерению оптических свойств, ИК-колебательных спектров, люминесценции, термостимулированной люминесценции. Принадлежность полосы в области 1800-2300 $\mathrm{cm}^{-1}$ валентным колебаниям комплекса с сильной водородной связью доказана на основе Ферми-резонансного возмущения в области $2080 \mathrm{~cm}^{-1}$ в виде „провала Эванса“ и полос $A, B, C$. Показано, что в состав этих комплексов входят ион $\mathrm{OH}^{-}$и молекула НF. Выявлена определяющая роль кислородных диполей $\mathrm{O}^{2-} V_{a}^{+}$в эффективности агрегации и градиентном распределении центров окраски, а также в радиационной стойкости ионов гидроксила. Показано, что продукты радиационного распада ионов $\mathrm{OH}^{-}$ стимулируют, а диполей $\mathrm{O}^{2-} V_{a}^{+}$подавляют образование положительно заряженных центров окраски.
\end{abstract}

Работа выполнена при поддержке программы II.10.1 фундаментальных исследований СО РАН на 2013-2016 гг. и при частичной поддержке проекта в рамках постановления Правительства РФ № 218 (договор № 9110R321).

Измерения выполнялись с использованием оборудования ЦКП „Байкальский центр нанотехнологий“.

DOI: $10.21883 /$ FTT.2017.06.44484.268

\section{1. Введение}

Кристаллы фторида лития (LiF) используются в качестве дозиметров ионизирующего излучения, как лазерные среды на центрах окраски, в оптических элементах конструктивных блоков приборов, в качестве объектов воздействия фемтосекундных импульсов лазерного излучения и др. [1-4].

Известно, что в результате облучения кристаллов $\mathrm{LiF}$ ионизирующим излучением создаются центры окраски (ЦО). Возможности практического применения фторида лития расширяются при активировании кристаллов примесями гидроксила $\left(\mathrm{OH}^{-}\right)$, кислорода, катионами двухвалентных металлов за счет направленного радиационного создания в нем люминесцирующих ЦО. Однако до сих пор не всегда удается получать кристаллы с заранее заданными свойствами, поскольку детальные механизмы образования радиационно-наведенных дефектов остаются до конца неясными.

Нами была поставлена цель установить зависимость между содержанием различных видов кислородсодержащих примесей и радиационной стойкостью фторида лития и примеси гидроксила в нем. Задача исследования состояла также в выяснении причин объемного градиента концентрации простых и агрегатных ЦО в $\gamma$-облученных кристаллах $\mathrm{LiF}$, выращенных на воздухе, a также причин разной температурной стабильности заряженных ЦО и разной эффективности образования молекулярных комплексов с водородной связью (МК с Н-связью) по объему кристалла.

\section{2. Образцы и экспериментальные методики}

В работе исследовались образцы, выколотые из кристалла LiF, имеющего вертикальный градиент распределения примеси, полученный в процессе выращивания кристалла. Из верхней части (начало роста кристалла) был выколот образец № 1, из нижней части (конец роста кристалла) - образец № 2 .

Кристалл выращивался методом Киропулоса на воздухе. После выращивания вся буля кристалла облучалась $\gamma$-источником $\mathrm{Co}^{60}$ до дозы $2.58 \cdot 10^{2} \mathrm{C} / \mathrm{kg}$ при комнатной температуре. Содержание катионных примесей определялось методом полуколичественного атомноэмиссионного спектрального анализа. Примеси гидроксила и комплексов металл-гидроксил анализировались по ИК-колебательным спектрам, полученным с помощью Фурье-спектрометра Bruker Vertex 70. Спектры поглощения в УФ- и видимом диапазонах измерялись 
с помощью спектрофотометра Perkin Elmer Lambda 950. Спектры люминесценции измерялись на лазерном конфокальном микроскопе МТ-200. Облучение кристаллов для исследования спектров термостимулированной люминесценции (ТСЛ) производилось с помощью рентгеновской трубки БСВ-7 (ток $2.5 \mathrm{~mA}$, напряжение $40 \mathrm{kV}$ ). Измерение кривых ТСЛ осуществлялось при скорости нагрева $0.25^{\circ} \mathrm{C} / \mathrm{s}$.

\section{3. Экспериментальные результаты и их обсуждение}

3.1. Радиационно-наведенные простые и агрегатные ЦО в LiF и молекулярные комплексы с H-связью, поглощающе в области 1800-2300 $\mathrm{cm}^{-1}$. На рис. $1, a$ представлены спектры поглощения $\gamma$-облученных образцов № 1 и 2. Видно, что в образце № 2 концентрация электронных ЦО $F, F_{2}, F_{3}(R), F_{4}(N)$ существенно выше, чем в образце № 1 . ИК-спектры $\gamma$-облученных кристаллов (рис. $1, b$, кривые 1 и 2) свидетельствуют о том, что в кристаллах присутствуют комплексы магний-гидроксил (пики 3660, $\left.3610,3550,3430 \mathrm{~cm}^{-1}\right)$ наряду с ионами гидроксила в узлах замещения, не возмущенными примесными катионами $\left(3720 \mathrm{~cm}^{-1}\right)[5,6]$. В указанных работах полоса $3430 \mathrm{~cm}^{-1}$ не наблюдалась в спектрах кристаллов с примесью магния и гидроксила. Значит, эту полосу, учитывая ее сдвиг в длинноволновую область, можно приписать более сложным комплексам с участием гидроксила, среди которых могут быть комплексы, включающие $M e^{3+}$ (Me - металл) и $\mathrm{O}^{2-}$. По результатам спектрального анализа трехвалентные металлы $\mathrm{Al}, \mathrm{Fe}$ присутствуют в исследуемом кристалле (см. таблицу).

Анализируя рис. 1, можно заключить, что образование ЦО в кристаллах $\mathrm{LiF}$ с кислородсодержащими примесями не коррелирует с центрами с водородной связью, ответственными за поглощение в диапазонах $1800-2300$ и $2800-3700 \mathrm{~cm}^{-1}$. В образце № 2 в процессе облучения эффективно образуются электронные ЦО $\left(F, F_{2}, F_{3}, F_{4}\right)$ (рис. $1, a$, кривая 2) и соответственно дырочные центры, среди которых $V_{3}$-центры по литературным данным являются стабильными при комнатной температуре. Образование дырочных центров в процессе облучения не ставится под сомнение, поскольку электронные ЦО и дырочные центры являются комплементарными. Дырочные Н-центры, которые тождественны междоузельным атомам фтора $\mathrm{F}_{i}^{0}$, по мнению авторов

Содержание катионных и других примесей в $\mathrm{LiF}: \mathrm{OH}$

\begin{tabular}{c|c|c|c|c|c}
\hline \multirow{2}{*}{$\begin{array}{c}\text { Номер } \\
\text { образца }\end{array}$} & \multicolumn{5}{|c}{ Концентрация, \% } \\
\cline { 2 - 6 } & $\mathrm{Si}$ & $\mathrm{Al}$ & $\mathrm{Mg}$ & $\mathrm{Fe}$ & $\begin{array}{c}\text { Другие } \\
\text { металлы }\end{array}$ \\
\hline 1 & 0.001 & 0.001 & 0.001 & 0.001 & $<0.001$ \\
2 & 0.002 & 0.003 & 0.002 & 0.003 & $<0.001$
\end{tabular}
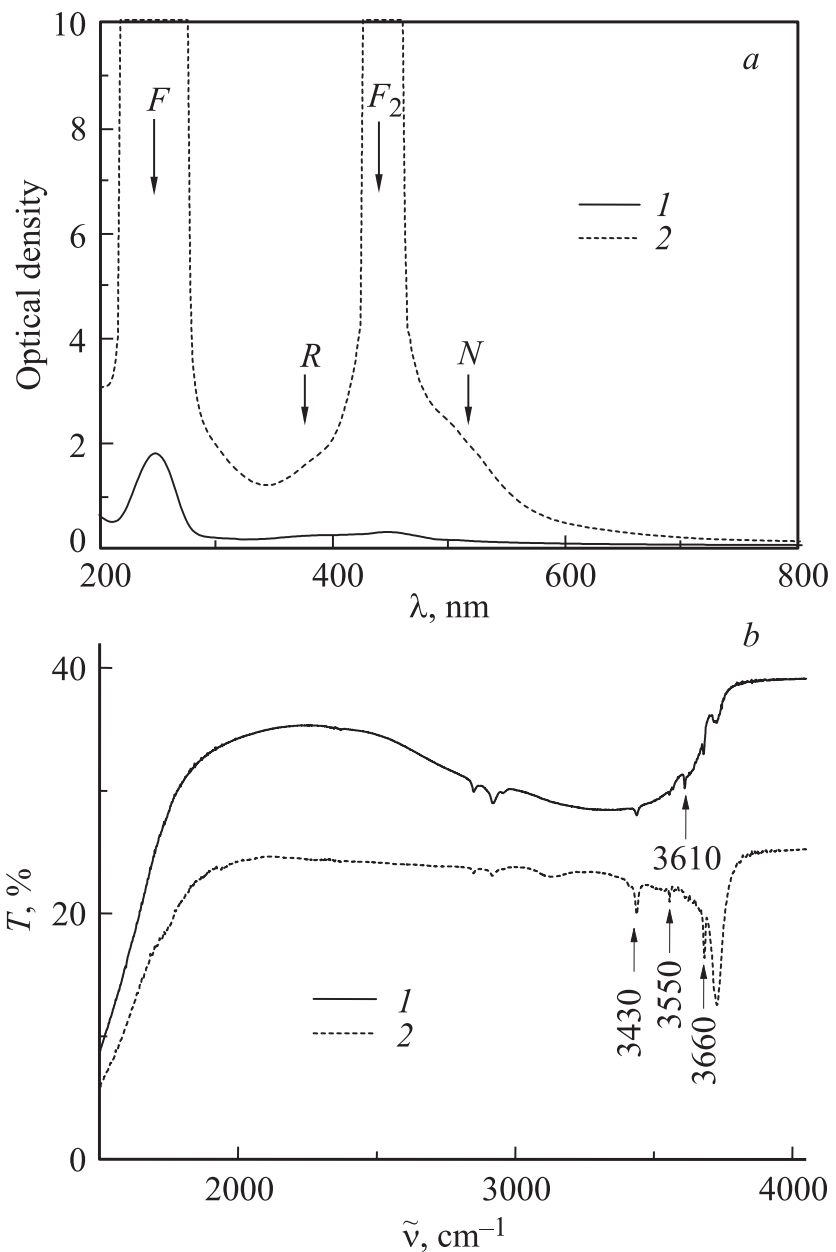

Рис. 1. Спектры поглощения в УФ- и видимой области $(a)$ и спектры пропускания в ИК-области $(b) \gamma$-облученных дозой $2.58 \cdot 10^{2} \mathrm{C} / \mathrm{kg}$ образцов № 1 и 2 кристалла $\mathrm{LiF}$, измеренные при комнатной температуре. Номера кривых соответствуют номерам образцов.

работ $[7,8]$, участвуют в образовании комплексов с водородной связью типа ОН. . $n \mathrm{~F}_{i}^{0}$ (где $n=1,2,3, \ldots$; $\mathrm{F}_{i}^{0}$ - междоузельный атом галоида, комплементарный $F$-центру окраски), имеющих поглощение в области $1800-2200 \mathrm{~cm}^{-1}$. Однако в кристалле с высокой плотностью электронных ЦО и соответственно атомов $\mathrm{F}_{i}^{0}$ нет комплексов, поглощающих в области $1800-2300 \mathrm{~cm}^{-1}$ (рис. $1, b$, кривая 2). Значит, модель центров типа $\mathrm{OH} . . \mathrm{F}_{i}^{0}$, образующихся при радиационном облучении кристаллов $\mathrm{LiF}: \mathrm{OH}$ и имеющих поглощение в области $1800-2300 \mathrm{~cm}^{-1}$, является необоснованной.

В нижней части кристалла (образец № 2), где нет комплексов с Н-связью с полосами $1800-2300 \mathrm{~cm}^{-1}$, радиационностойкой оказывается примесь ионов гидроксила (как свободных, так и в комплексах с металлом). При значительной дозе $\gamma$-облучения концентрация $\mathrm{OH}^{-}$ практически не изменяется (рис. $1, b$, кривая 2), т.е. в образце № 2 не формируются продукты радиационного разрушения ионов $\mathrm{OH}^{-}$, такие как, например, $\mathrm{O}_{2}^{-}, \mathrm{O}_{2}^{0}$, 
HF [9-12]. Из этого следует вывод, что в кристаллах, в которых образуются комплексы с Н-связью, именно кислород- и фторсодержащие продукты радиационного распада ионов гидроксила могут быть второй структурной единицей $(B)$ комплексов $\mathrm{OH}^{-} \ldots B$, ответственных за ИК-полосы в области $1800-2300 \mathrm{~cm}^{-1}$. Среди них наиболее вероятным кандидатом является молекула $\mathrm{HF}$, поскольку она может находиться в узле и в междоузлии, что позволяет структурным единицам комплекса с Н-связью типа $\mathrm{OH}^{-} \ldots \mathrm{FH} \ldots \mathrm{F}$ регулировать взаимное расположение. Другими (кислородсодержащими) продуктами радиационного распада, имеющими возможность образовывать Н-связи с $\mathrm{OH}^{-}$, могут быть молекулярный ион кислорода $\mathrm{O}_{2}^{-}$или молекула кислорода $\mathrm{O}_{2}^{0}$, однако полосы поглощения МК с Н-связью при этом должны быть более коротковолновыми. Это обусловлено тем, что частота колебаний Н-связи $A \mathrm{H} \ldots B$, равная $\sim 2000 \mathrm{~cm}^{-1}$, соответствует расстоянию между атомами $A$ и $B$ в интервале $2.2-2.55 \AA$ [13]. Расстояние по диагонали грани куба в $\mathrm{LiF}$ в направлении $\langle 110\rangle$ составляет $2.85 \AA$, поэтому комплекс с Н-связью $\mathrm{OH}^{-} \ldots \mathrm{O}_{2}^{0}$ должен иметь поглощение в более коротковолновой области, чем $2000 \mathrm{~cm}^{-1}$ [13].

Полоса в области $1800-2300 \mathrm{~cm}^{-1}$ часто состоит из субполос. Авторы работ $[7,8]$ объясняют это „разрыхлением“" комплекса с водородной связью вследствие взаимодействия с дополнительными атомами фтора. В этом случае должно наблюдаться наложение полос разных комплексов с Н-связью в этой спектральной области. Доказательством того, что сложная полоса в области $1800-2300 \mathrm{~cm}^{-1}$ принадлежит комплексу с Н-связью одной природы, а не нескольким различным комплексам, проявляющим так называемое „разрыхление“, является ее Ферми-резонансное расщепление.

3.2. Ферми-резонансное возмущение полосы $1800-2300 \mathrm{~cm}^{-1}$ в облученных кристаллах $\mathrm{LiF}$ с примесями гидроксила и магния. Ферми-резонанс комплексов с сильной и очень сильной Н-связью описан в работах $[14,15]$. Ферми-резонанс проявляется в виде возмущений широкой полосы валентных колебаний МК с Н-связью. Для ИК-спектров характерны три типа проявления Ферми-резонанса: 1) наложение полосы деформационных колебаний на полосу валентных колебаний без возмущения ее профиля; 2) „окна прозрачности“ Эванса; 3) фрагментация полосы валентных колебаний на полосы $A, B, C$. В результате Ферми-резонанса происходит либо „прорезывание“ профиля широкой полосы валентных колебаний в виде „провала Эванса“ (в случае одного деформационного колебания), либо расщепление широкой основной полосы на три подполосы $A, B, C$ (если у МК два деформационных колебания).

Для $\gamma$-облученных кристаллов LiF нами были выявлены все три типа спектров с проявлениями Ферми-резонанса в области $1800-2300 \mathrm{~cm}^{-1}$ (рис. 2).

Нами было исследовано большое число кристаллов $\mathrm{LiF}$ с гидроксилом и магнием, облученных разными до-

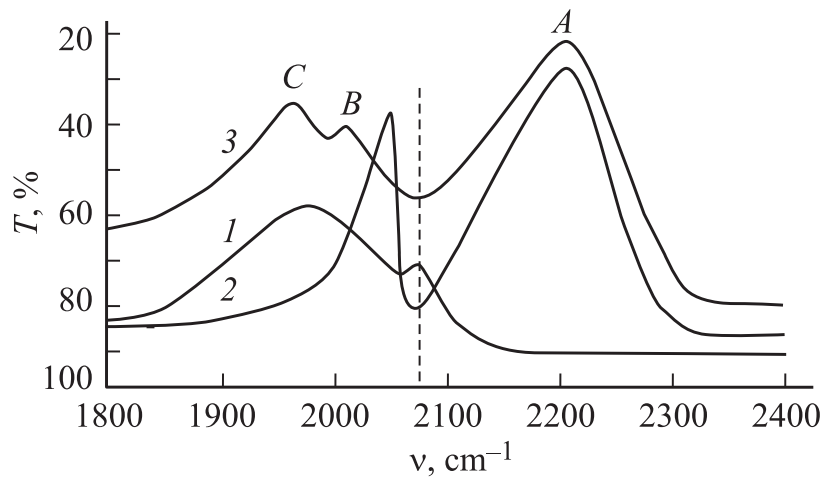

Рис. 2. Ферми резонансное расщепление полосы в области 1800-2300 $\mathrm{cm}^{-1}: 1-$ ИК-спектр пропускания $\mathrm{LiF}: \mathrm{OH}$, $\mathrm{Mg}$ (индекс кристалла Г7), облученного нейтронами дозой $8.7 \cdot 10^{15} \mathrm{~cm}^{2}$ при $T=40 \mathrm{~K}$ (не возмущенная Фермирезонансом полоса), 2 - ИК-спектр пропускания $\mathrm{LiF}: \mathrm{OH}$ (индекс кристалла 194), $\gamma$-облученного до дозы $2.58 \cdot 10^{3} \mathrm{C} / \mathrm{kg}$ при $355 \mathrm{~K}$ и отожженного при $T<450 \mathrm{~K}$ („провал Эванса“), 3 - ИК-спектр пропускания $\mathrm{LiF}: \mathrm{OH}, \gamma$-облученного до дозы $5.16 \cdot 10^{4} \mathrm{C} / \mathrm{kg}$ при $190 \mathrm{~K}$ и отожженного до $T=450 \mathrm{~K}$ (полосы $A, B, C)$.

зами ионизирующих излучений при различных условиях облучения. Концентрация примеси в кристаллах также значительно различалась. Однако Ферми-резонансное расщепление ИК-полосы в области $1800-2300 \mathrm{~cm}^{-1}$ наблюдалось не во всех кристаллах. Это связано с тем, что на колебания МК с Н-связью значительное влияние оказывают центры окраски и другие дефекты, образующиеся при облучении. Находясь в решетке $\mathrm{LiF}$ вблизи комплексов с Н-связью, они влияют на фононный спектр решетки и на комплекс с водородной связью и могут подавлять резонансные явления.

На рис. 2 (кривая 1) в области $v=2080 \mathrm{~cm}^{-1}$ на линии спектра валентных колебаний выделилась узкая полоса. Данный спектр отражает полосу поглощения валентных колебаний, не возмущенную Ферми-резонансом. На рис. 2 (кривая 2) представлена одна из стадий отжига $(T<450 \mathrm{~K})$ кристалла $\mathrm{LiF}: \mathrm{OH}$, $\gamma$-облученного до дозы $2.58 \cdot 10^{3} \mathrm{C} / \mathrm{kg}$ при $355 \mathrm{~K}$. В области $v=2080 \mathrm{~cm}^{-1}$ наблюдается „провал Эванса“. На рис. 2 (кривая 3) представлена стадия отжига кристалла $\mathrm{LiF}: \mathrm{OH}$, облученного до дозы $5.16 \cdot 10^{4} \mathrm{C} / \mathrm{kg}$ при $190 \mathrm{~K}$. Линия спектра распалась на полосы $A, B, C$, характерные для Ферми-резонансного расщепления. Сравнивая все три спектра, можно отметить наличие пика (рис. 2, кривая 1), провала (рис. 2, кривая 2) и глубокой впадины (рис. 2, кривая 3) на одном и том же месте спектра в области $v=2080 \mathrm{~cm}^{-1}$. Учитывая, что частота деформационных колебаний $\delta\left(1115\right.$ и $\left.1135 \mathrm{~cm}^{-1}\right)$ [16] приблизительно в 2 раза меньше частоты валентных колебаний $v_{s}$ в области $1800-2300 \mathrm{~cm}^{-1}$, можно сделать предположение о наличии Ферми-резонанса $\left(v_{s} \sim 2 \delta\right)$, следствием которого является образование пика, провала и впадины в области $v=2080 \mathrm{~cm}^{-1}$ (рис. 2). Таким 
образом, в области $1800-2300 \mathrm{~cm}^{-1}$ имеет поглощение комплекс с сильной водородной связью, структурными единицами которого являются ион $\mathrm{OH}^{-}$и продукт, образовавшийся вследствие радиационного распада гидроксила. Этим продуктом может быть молекула НF, связанная в свою очередь с ионом фтора, если у комплекса два деформационных колебания. Комплекс может иметь вид: ОН...FН ...F или ОН...F ... НF. На взаимные расстояния между структурными единицами комплекса в зависимости от примесного состава и условий облучения оказывают возмущающее действие окружающие дефекты.

3.3. Влияние примесного состава на термостимулированную люминесценцию кристалла $\operatorname{LiF}$ и агрегацию ЦО. Для выяснения причин вертикального (от верхней части кристалла к нижней) концентрационного градиента ЦО были исследованы кривые ТСЛ исследуемых образцов.

B LiF: (Mg, Ti) наблюдается несколько пиков термостимулированной люминесценции, среди них пик 5 используется в термолюминесцентной дозиметрии гаммаизлучения в качестве рабочего пика [1]. Однако эти пики ТСЛ наблюдаются и в кристаллах, специально не легированных примесями магния и титана. Эффективность термолюминесцентных дозиметров ионизирующего излучения на основе фтористого лития зависит от влияния кислородных и водородных примесей, которые неконтролируемым образом всегда присутствуют в кристаллах $\mathrm{LiF}$ даже при выращивании в инертной атмосфере. В исследуемых нами кристаллах присутствуют катионные примеси (см. таблицу) и примеси „свободного“ и связанного с магнием $[5,6]$ гидроксила (рис. $1, b)$. Автор работ $[5,6]$ считает, что если в ИК-спектре наряду с полосами комплексов магний-гидроксил присутствуют полосы „свободного“ гидроксила (как в исследуемом нами кристалле), то все имеющиеся в кристалле ионы магния связаны с ионами гидроксила. Таким образом, в $\gamma$-облученном кристалле $\mathrm{LiF}: \mathrm{OH}$ все ионы магния связаны с ионами гидроксила (рис. $1, b$ ). Связь всех ионов магния в комплексы $\mathrm{Mg}^{2+} \mathrm{OH}^{-} V_{c}^{-}\left(V_{c}^{-}-\right.$катионная вакансия) предполагает отсутствие диполей $\mathrm{Mg}^{2+} V_{c}^{-}$ в кристалле. Отсутствие простых диполей и агрегатов диполей $\mathrm{Mg}^{2+} V_{c}^{-}$подтвердили спектры ТСЛ (рис. 3, $a$ ), в которых нет пиков, связанных с диполями $\mathrm{Mg}^{2+} V_{c}^{-}$, а также с димерами и тримерами $\mathrm{Mg}^{2+} V_{c}^{-}[17,18]$.

Термопик образца № 1 имеет максимум при $255^{\circ} \mathrm{C}$, образца № 2 - при $273^{\circ} \mathrm{C}$. Эти термопики являются высокотемпературными, обусловленными примесью гидроксила. Такого мнения придерживаются авторы работ $[19,20]$. Они считают, что, когда ионы гидроксила связывают ионы $\mathrm{Mg}$ в комплексы $\mathrm{Mg}$-гидроксил в дозиметрических образцах типа $\mathrm{LiF}:(\mathrm{Mg}, \mathrm{Ti})$, в этой форме ионы магния не могут действовать как ловушки для стандартных термопиков 2, 4, 5. Высокотемпературные пики, обозначенные цифрами выше чем 5 (в нашем случае это пики при 255 и $273^{\circ} \mathrm{C}$ ), соответствуют ловушкам, лежащим глубже в пределах ширины запрещен-

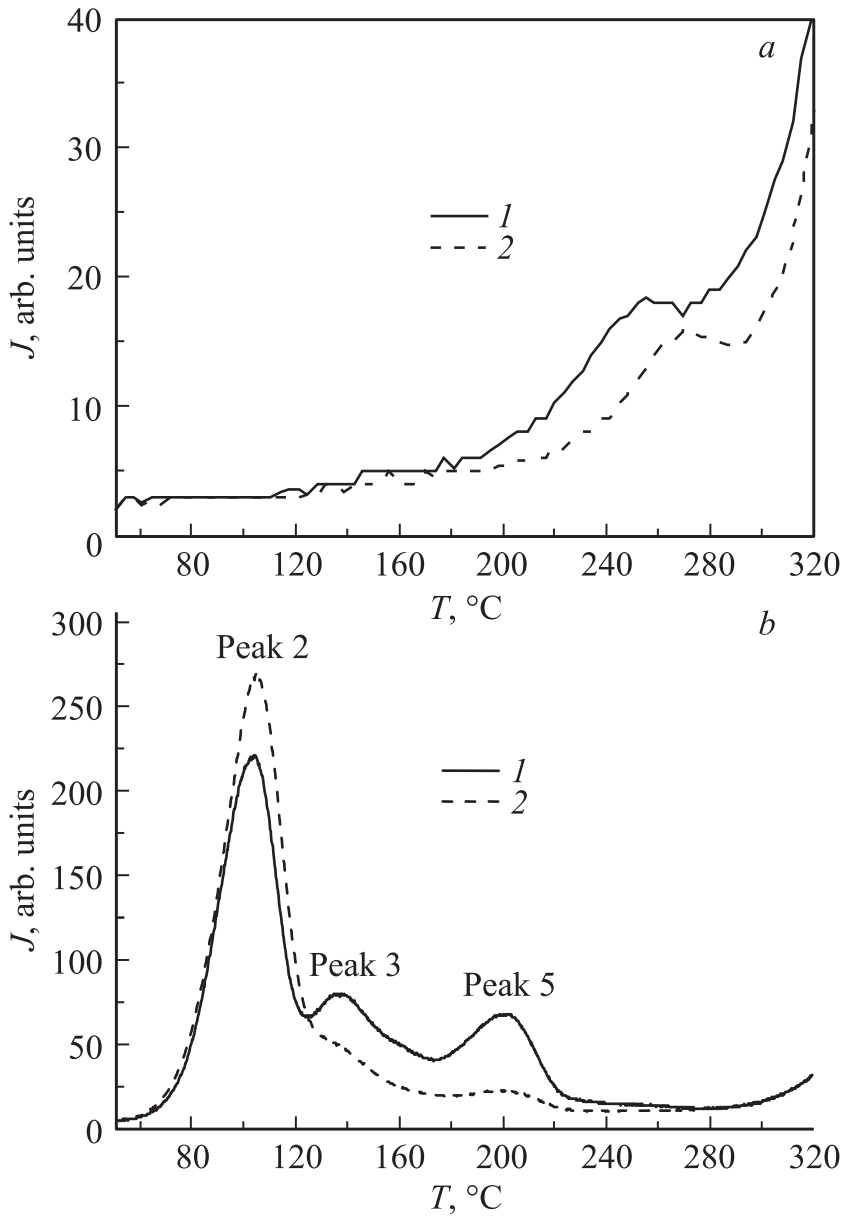

Рис. 3. Кривые термостимулированной люминесценции образцов № 1 и 2: $a-\gamma$-облученных до дозы $2.58 \cdot 10^{2} \mathrm{C} / \mathrm{kg}$, $b$ - отожженных при $600^{\circ} \mathrm{C}$ и повторно облученных рентгеновским излучением в течение $4 \mathrm{~h}$. Резкое возрастание интенсивности ТСЛ к температуре $320^{\circ} \mathrm{C}$ связано с проявлением теплового фона. Номера кривых соответствуют номерам образцов.

ной зоны, и электрону в этих глубоких уровнях захвата требуется больше тепловой энергии для освобождения. В качестве таких глубоких ловушек для носителей заряда, освобождаемых термически, рассматриваются ионы и комплексы гидроксила $[19,20]$.

Нами были измерены спектры термически отожженных при $600^{\circ} \mathrm{C}$ образцов № 1 и 2 (рис. $4, a, b$ ).

Из рис. 4 видно, что в ИК-спектрах присутствует полоса поглощения замещающих ионов гидроксила при $3720 \mathrm{~cm}^{-1}$ и исчезли полосы, соответствующие комплексам металл-гидроксил. В процессе отжига произошла диффузия примесных ионов, и ионы магния перестали быть связанными с ионами гидроксила. Значит, избыточный заряд иона $\mathrm{Mg}^{2+}$ должен компенсироваться катионной вакансией $V_{c}^{-}$, которая может находиться в соседнем узле или на большем расстоянии от иона магния. В случае нахождения в ближайшем узле будут образовываться диполи $\mathrm{Mg}^{2+} V_{c}^{-}$. 

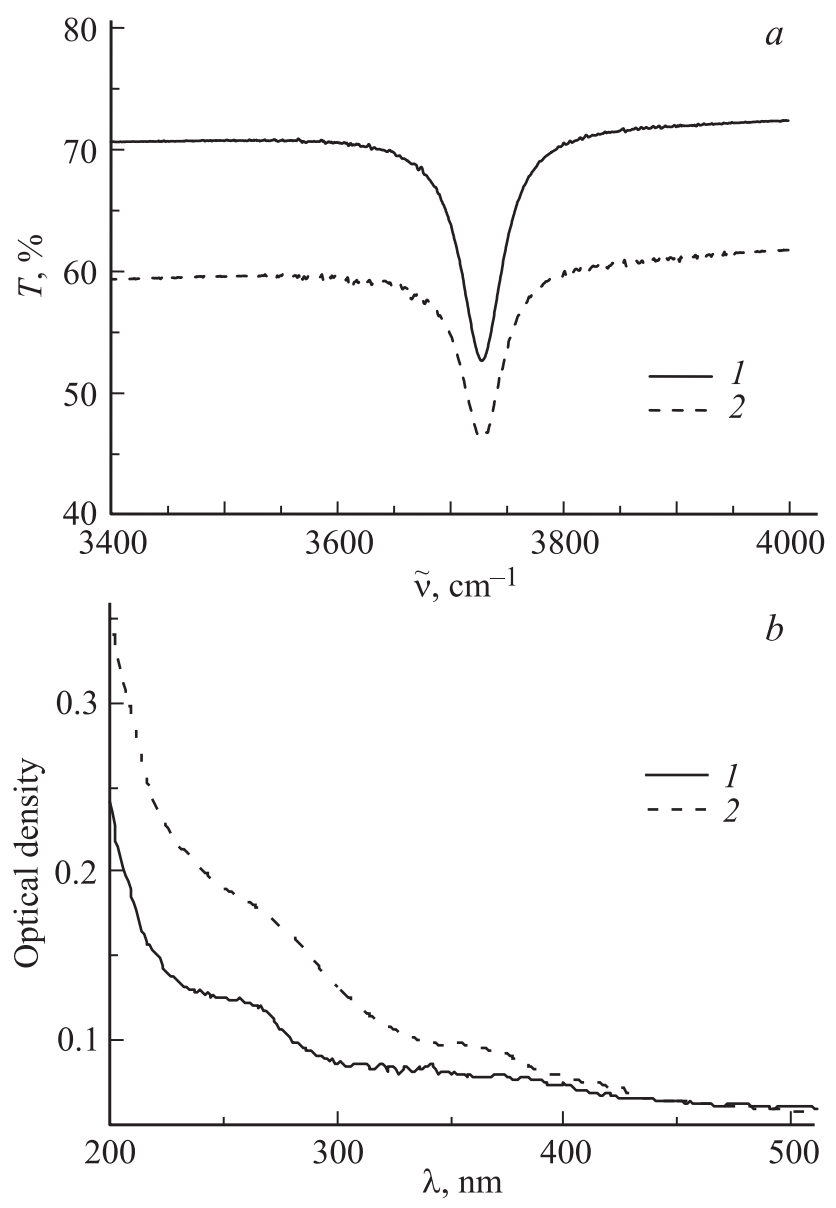

Рис. 4. Спектры образцов № 1 и 2 после отжига при $600^{\circ} \mathrm{C}$ и остывания до комнатной температуры в открытой печи в течение $10 \mathrm{~min} . a-$ спектры пропускания в ИК-области, $b-$ спектры поглощения в УФ- и видимой области. Номера кривых соответствуют номерам образцов.

Образование в результате отжига одиночных диполей $\mathrm{Mg}^{2+} V_{c}^{-}$, а также димеров и тримеров $\mathrm{Mg}^{2+} V_{c}^{-}$подтверждают кривые термостимулированной люминесценции отожженных кристаллов (рис. 3,b). В спектре ТСЛ образца № 1 (рис. 3,b) наблюдаются пики 2, 3 и 5 (при 100,135 и $200^{\circ} \mathrm{C}$ соответственно). Пик 2 , связанный с одиночными диполями $\mathrm{Mg}^{2+} V_{c}^{-}$, в образцах № 1 и 2 имеет мало различающуюся интенсивность ТСЛ, однако пик 5, связанный с димерами и тримерами $\mathrm{Mg}^{2+} V_{c}^{-}$ диполей $[17,18]$, намного интенсивнее в образце № 1 (рис. $3, b)$.

Малая интенсивность ТСЛ пика 5 в образце из нижней части обусловлена незначительной концентрацией димеров и тримеров $\mathrm{Mg}^{2+} V_{c}^{-}$диполей. Концентрация агрегатов диполей $\mathrm{Mg}^{2+} V_{c}^{-}$в образце № 2 меньше, однако концентрация примеси магния практически одинакова в обоих образцах (см. таблицу). Следовательно, в образце № 2 компенсатором избыточного заряда оставшихся после связывания в диполи $\mathrm{Mg}^{2+} V_{c}^{-}$ионов $\mathrm{Mg}^{2+}$ может быть ион кислорода $\mathrm{O}^{2-}$. Действительно, концентрация ионов $\mathrm{O}^{2-}$ в кристалле увеличивается к концу его роста. По мере роста кристалла на воздухе в расплаве происходит реакция взаимодействия: $4 \mathrm{Li}+\mathrm{O}_{2}=2 \mathrm{Li}_{2} \mathrm{O}$. Образование окиси лития $\mathrm{Li}_{2} \mathrm{O}$ и растворение ее в расплаве $\mathrm{LiF}$ приводит к обогащению расплава диполями $\mathrm{O}^{2-} V_{a}^{+}$ $\left(V_{a}^{+}\right.$- анионная вакансия). Наличие в расплаве одновременно двухвалентных ионов металла (в частности, $\mathrm{Mg}$ ) и кислорода приводит к появлению в кристаллической решетке $\mathrm{Me}^{2+} \mathrm{O}^{2-}$ комплексов замещения. Следствием образования новых комплексов является „связывание“ ионов магния в комплексы преимущественно с кислородом, а не с катионными вакансиями. Таким образом, в конечной части кристалла уменьшается количество агрегатов диполей $n\left(M e^{2+} V_{c}^{-}\right)$, которые замещаются комплексами $n\left(\mathrm{Me}^{2+} \mathrm{O}^{2-}\right)$. Следствием такого замещения является уменьшение интенсивности ТСЛ пика 5 в нижней части кристалла (рис. 3,b). Об увеличении концентрации кислородных примесей в расплаве в конце роста свидетельствуют спектры поглощения в УФ- и видимой области (рис. 4, $b$ ). Интенсивность поглощения кислородных примесей в образце № 2 (рис. 4, $b$, кривая 2) больше, чем в образце № 1. Увеличение интенсивности полос в спектре в диапазоне от 300 до $200 \mathrm{~nm}$ и далее в область вакуумного ультрафиолета свидетельствует об увеличении концентрации одиночных диполей $\mathrm{O}^{2-} V_{a}^{+}$и $\mathrm{Mg}^{2+} \mathrm{O}^{2-}$ и их агрегатов [9,21].

Таким образом, градиент суммарной концентрации ЦО в направлении от верха к низу кристалла можно объяснить накоплением кислородных примесей в кристалле к концу его роста. Действительно, поскольку кристалл облучался одной и той же дозой излучения, градиент окраски связан только с градиентом примеси. Анализ примесного катионного состава (см. таблицу) показал практически однородное распределение примесей $\mathrm{Si}, \mathrm{Al}$, $\mathrm{Mg}$, Fe по всей буле кристалла. Концентрация ионов гидроксила даже несколько уменьшилась к концу роста (рис. 4,a). Поэтому увеличение концентрации ЦО и повышение эффективности агрегации ЦО в нижней части кристалла (в образце № 2) связаны с накоплением к концу роста кислородных диполей $\mathrm{O}^{2-} V_{a}^{+}$и $\mathrm{Me}^{2+} \mathrm{O}^{2-}$ и их агрегатов.

3.4. Влияние примеси кислорода на люминесценцию и эффективность агрегации ЦО и радиационную стойкость ионов гидроксила в LiF. Спектры люминесценции были измерены при возбуждении светом с длиной волны 470, 530 и $640 \mathrm{~nm}$. Спектры, представленные на рис. 5, показывают, что в образце № 1 наблюдается люминесценция $F_{3}^{+}$-центров и отсутствует люминесценция $F_{2}$-центров. В образце № 2, наоборот, преобладает люминесценция $F_{2}$-центров. Люминесценция $F_{2}^{+}$-центров, наблюдающаяся в зависимости от влияния примесей в области 800-1000 nm, отсутствует в спектрах обоих образцов.

В образце № 1 из верхней части кристалла присутствие положительно заряженных центров предполагает наличие стабилизирующих эти центры дефектов. Такими 


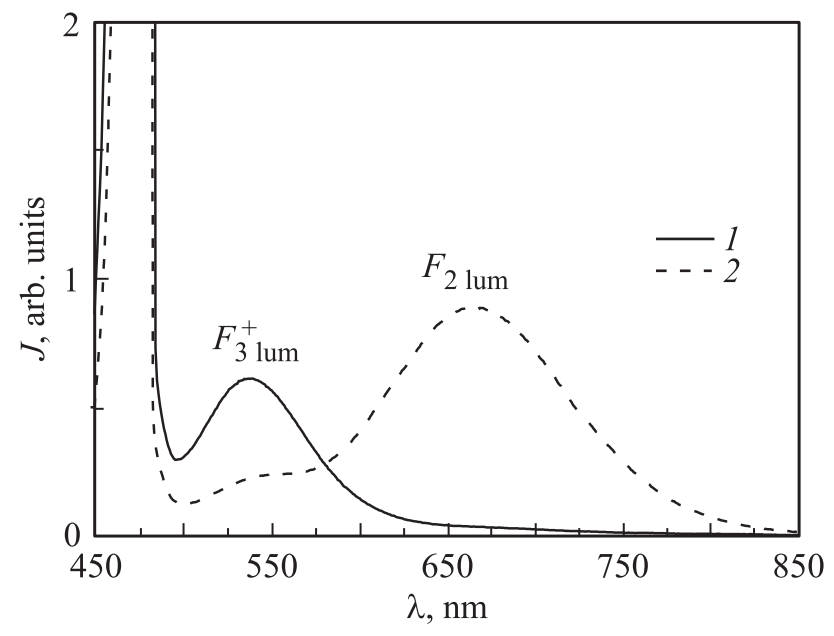

Рис. 5. Спектры люминесценции образцов № 1 и 2 кристалла $\operatorname{LiF}\left(\lambda_{\mathrm{ex}}=470 \mathrm{~nm}\right)$. Номера кривых соответствуют номерам образцов.

дефектами могут быть ионы $\mathrm{O}^{2-}$. Поставщиками таких центров являются ионы гидроксила и диполи $\mathrm{O}^{2-} V_{a}^{+}$.

О радиационном разложении ионов гидроксила свидетельствует образование широкой ИК-колебательной полосы в области $2400-3720 \mathrm{~cm}^{-1}$ и соответственно $U$-центров в образце № 1 [12]. Следовательно, в процессе $\gamma$-облучения происходили радиационно-химические реакции $[9,10,22-24]$ :

$$
\begin{aligned}
& \mathrm{OH}^{-}+h v \rightarrow \mathrm{O}^{-}+\mathrm{H}_{i}^{0}, \\
& 2 \mathrm{OH}^{-}+h v \rightarrow \mathrm{O}_{2}^{-}+e+V_{a}^{+}+2 \mathrm{H}_{i}^{0}, \\
& \mathrm{O}^{-}+e+V_{a}^{+} \rightarrow \mathrm{O}^{2-} V_{a}^{+}, \\
& e+V_{a}^{+} \rightarrow F, \\
& \mathrm{O}^{2-} V_{a}^{+}+F \rightarrow F_{2}^{+} \mathrm{O}^{2-}, \\
& V_{a}^{+}+F \rightarrow F_{2}^{+}, \\
& \mathrm{O}^{2-} V_{a}^{+}+F_{2}^{+}+e \rightarrow F_{3}^{+} \mathrm{O}^{2-}, \\
& F_{2}^{+}+F \rightarrow F_{3}^{+}, \\
& F_{2}^{+}+e \rightarrow F_{2}, \\
& \mathrm{O}^{2-} V_{a}^{+}+F_{2} \rightarrow F_{3}^{+} \mathrm{O}^{2-}
\end{aligned}
$$

Диполи $\mathrm{O}^{2-} V_{a}^{+}$становятся подвижными при температурах выше комнатной [21]. $F$ - и $F_{2}$-центры также неподвижны при комнатной температуре. Поэтому, по нашему мнению, реакции (4) и (6) идут малоэффективно. В то же время $F_{2}^{+}$-центры подвижны при комнатной температуре [1,24], поэтому реакция (5) может легко осуществляться. В связи с этим концентрация стабильных $F_{3}^{+}$-центров будет расти за счет уменьшения концентрации $F_{2}^{+}$-центров в образце № 1 , в котором происходит распад ионов гидроксила. Ионы гидроксила в образце № 2 не распадаются под действием радиации (рис. $1, b$, кривая 2), поэтому приведенные радиационно-химические реакции в нем не происходят, и стабильные $F_{3}^{+}$-центры образуются неэффективно.

Диполи $\mathrm{O}^{2-} V_{a}^{+}$и агрегаты диполей $n \mathrm{O}^{2-} V_{a}^{+}$, встроенные в решетку в результате роста кристалла, под воздействием радиационных излучений эффективно распадаются с протеканием реакций $[9,10]$

$$
\begin{gathered}
\mathrm{O}^{2-} V_{a}^{+} \rightarrow \mathrm{O}^{-}+e^{-}+V_{a}^{+}, \\
V_{a}^{+}+e^{-} \rightarrow F, \\
2 \mathrm{O}^{2-} V_{a}^{+} \rightarrow \mathrm{O}_{2}^{-}+3 e^{-}+3 V_{a}^{+}, \\
2 \mathrm{O}^{2-} V_{a}^{+} \rightarrow \mathrm{O}_{2}^{0}+4 e^{-}+3 V_{a}^{+} .
\end{gathered}
$$

Высокая концентрация диполей $\mathrm{O}^{2-} V_{a}^{+}$в нижней части кристалла является причиной радиационной стойкости ионов гидроксила в образце № 2. В результате реакции (7) образуются анионные вакансии, электроны и ион $\mathrm{O}^{-}$. Анионные вакансии и электроны, объединившись, образуют $F$-центры, а свободные ионы $\mathrm{O}^{-}$ остаются в результате этой реакции. Избыточное количество ионов $\mathrm{O}^{-}$вызывает реакции восстановления ионов гидроксила, а именно водород $\mathrm{H}_{i}^{0}$, образовавшийся в результате реакции (1), захватывается ионом $\mathrm{O}^{-}$, восстанавливая ион $\mathrm{OH}^{-}$по реакции

$$
\mathrm{O}^{-}+\mathrm{H}_{i}^{0} \rightarrow \mathrm{OH}^{-} .
$$

Поэтому большое количество диполей $\mathrm{O}^{2-} V_{a}^{+}$в нижней части кристалла ответственно за радиационную стойкость ионов гидроксила в образце № 2 .

С другой стороны, радиационно-химические реакции распада диполей $\mathrm{O}^{2-} V_{a}^{+}$поставляют дополнительные анионные вакансии и электроны, что способствует интенсивному образованию центров окраски (рис. $1, a$, кривая 2). УФ-спектры демонстрируют значительно большее содержание кислородных дефектов в нижней части кристалла, чем в верхней (рис. 4, $b$ ). Следовательно, кислородные примеси в образце № 2 находятся не только в виде одиночных диполей, но и в виде агрегатов диполей. Агрегаты диполей стимулируют образование агрегатных центров окраски, причем $F$-центры образуются одновременно с $F$-агрегатными центрами [25]. Автор работы [10] считает, что реакция (9) в LiF предпочтительнее, чем реакция (8). Следовательно, в результате реакций (8) и (9) образуется некоторый недостаток анионных вакансий по сравнению с электронами. Этим объясняется, что в образце № 2 люминесценция $F_{2}$-центров значительно преобладает над люминесценцией $F_{3}^{+}$-центров. Таким образом, повышенная концентрация диполей $\mathrm{O}^{2-} V_{a}^{+}$в образце № 2 подавляет образование положительно заряженных ЦО и вызывает эффективное образование нейтральных агрегатных центров окраски. 


\section{4. Заключение}

В результате проведенных исследований можно сделать следующие выводы.

Образование электронных и дырочных центров окраски в кристаллах LiF с кислородсодержащими примесями не влияет на создание комплексов с водородной связью, поглощающих в области $1800-2300 \mathrm{~cm}^{-1}$. Этот экспериментальный факт ставит под сомнение идентификацию полос в области $1800-2300 \mathrm{~cm}^{-1}$ как принадлежащих центрам типа ОН. . . $n \mathrm{~F}_{i}^{0}$.

Ферми-резонансное расщепление полосы в области $1800-2300 \mathrm{~cm}^{-1}$, впервые обнаруженное нами, доказывает, что полосы принадлежат комплексам с сильной водородной связью. Структурными единицами этого комплекса является ион гидроксила $\mathrm{OH}^{-}$и продукт, образовавшийся вследствие радиационного распада иона гидроксила (вероятнее всего, молекула НF).

Градиент суммарной концентрации ЦО в направлении от верха к низу растущего на воздухе кристалла $\mathrm{LiF}$ можно объяснить накоплением кислородных примесей в кристалле к концу его роста. Среди кислородных примесей главную роль играют диполи $\mathrm{O}^{2-} V_{a}^{+}$и их агрегаты.

Продукты радиационного распада ионов $\mathrm{OH}^{-}$стимулируют образование положительно заряженных ЦО $\mathrm{F}_{3}^{+}$, в то время как кислородные диполи $\mathrm{O}^{2-} V_{a}^{+}$и их агрегаты подавляют образование положительно заряженных ЦО.

Радиационная стойкость ионов гидроксила в LiF обусловлена реакциями его восстановления после радиационно-химического распада, вызванными повышенной концентрацией диполей $\mathrm{O}^{2-} V_{a}^{+}$и их агрегатов, поставляющих реагенты восстановления.

\section{Список литературы}

[1] А.И. Непомнящих, Е.А. Раджабов, А.В. Егранов. Центры окраски и люминесценция кристаллов LiF. Наука, Новосибирск (1984). 112 с.

[2] Н.А. Иванов, Д.В. Иншаков, И.А. Парфианович, В.М. Хулугуров. Письма в ЖТФ 12, 1250 (1986).

[3] L.C. Courrol, R.E. Samad, L. Gomes, I.M. Ranieri, S.L. Baldochi, A.Z. de Freitas, N.D. Vieira, Jr., Opt. Lett. 12, 288 (2004).

[4] L. Bryukvina. J. Lumin. 162, 145 (2015).

[5] T.G. Stoebe. J. Phys. Chem. Solids 28, 1375 (1967).

[6] T.G. Stoebe. J. Phys. Chem. Solids 31, 1291 (1970).

[7] П.Д. Алексеев, Т.И. Баранов. ФТТ 22, 1213 (1980).

[8] Л.А. Лисицына, В.М. Лисицын. ФТТ 55, 2183 (2013).

[9] E. Freytag. Z. Phys. 177, 206 (1964).

[10] A. Chandra. J. Chem. Phys. 51, 1499 (1969).

[11] Л.И. Брюквина. Изв. вузов. Физика 9, 101 (1988).

[12] Л.И. Брюквина, В.М. Хулугуров. ФТТ 30, 916 (1988).

[13] Дж. Пиментел, О. Мак-Клелан. Водородная связь. Мир, М. (1964). 462 c.

[14] A. Novak. Structure Bonding 18, 177 (1974).

[15] Н.Д. Соколов. Водородная связь. Наука, М. (1981). 238 с.
[16] Л.И. Брюквина, В.М. Хулугуров, И.А. Парфианович. ЖПС 48, 322 (1988).

[17] R.M. Grant, J.R. Cameron. J. Appl. Phys. 37, 3791 (1966).

[18] X.L. Yuan, S.W.S. McKeever. Phys. Status Solidi A 108, 545 (1988).

[19] W. Wachter, N.J. Vana, H. Aiginger. Nucl. Instrum. Meth. 175, 21 (1980).

[20] N. Takeuchi, K. Inabe, S. Nakamura. J. Mater. Sci. Lett. 2, 39 (1983).

[21] А.В. Егранов, Е.А. Раджабов. Спектроскопия кислородных и водородных примесных центров в щелочно-галоидных кристаллах. Наука, Новосибирск (1992). 161 с.

[22] H. Dotsch, W. Gebhardt, C.H. Martius. Solid State Commun. 3, 297 (1965).

[23] M.L. Meistrich. J. Phys. Chem. Solids 29, 1119 (1968).

[24] J. Nahum. Phys. Rev. 158, 814 (1967).

[25] Б.Д. Лобанов, В.М. Хулугуров, И.А. Парфианович. Изв. вузов. Физика 4, 81 (1978). 